\title{
SEISMIC RESPONSE VERIFICATION AND RETROFITTING OF RC BUILDING SUBJECTED TO 2014, CEPHALONIA EARTHQUAKES
}

\author{
Ioannis E. Kavvadias ${ }^{1}$, Ifigeneia P. Litina ${ }^{1}$, Varvara C. Kyriakidou ${ }^{1}$, Fani T. \\ Mamatsopoulou $^{1}$, Lazaros K. Vasiliadis ${ }^{1}$ \\ ${ }^{1}$ Democritus University of Thrace, Dept. of Civil Engineering, \\ Institute of Structural Mechanics and Earthquake Engineering \\ Vas. Sofias 12, 67100 Xanthi, Greece \\ \{ikavvadi, ilitina, varvkyri, fanimama, lvasilia\}@civil.duth.gr
}

Keywords: RC building, assessment, base isolation, metal braces

\begin{abstract}
In early 2014, strong earthquakes occurred on the Island of Cephalonia and buildings with significant design errors were heavily damaged. The building that is being studied is a two-storey reinforced concrete building, which was affected by the specific earthquakes. The structural model of the building is regular in plan as it consists of parallel frames arranged in dense grid but it is non regular in elevation as there are no infill walls located in the down floor. In the first part of this paper, the seismic assessment of the structure is presented. It is an attempt to verify the damages which occurred to the building during the earthquakes. In the second part of this paper, strategies for structural intervention are suggested. Firstly, it is intended to reduce the seismic demand of the structure through the implementation of base isolation systems. Specifically the appliance of lead rubber bearings (LRB) and friction pendulum systems (FPS) has been studied. Secondly, it is intended to increase the stiffness of the ground floor by placing metal braces. The study is based on results from nonlinear analyses. The analyses that have been used are the pushover analysis and the nonlinear time history analysis.
\end{abstract}




\section{INTRODUCTION}

Heavy earthquakes occurred on the Cephalonia Island in early 2014. The RC building studied in this work, is an existing in the area building which was subjected to the earthquakes. After infield investigation enough data have been gathered to assess the building. The basic purpose of the paper is the verification of the actual seismic behavior of the building and afterwards the intervention in its structural system in order to improve its seismic behavior.

A crucial characteristic of the structure that must be taken into consideration is that the building is regular in plan but irregular in elevation. The abrupt reduction of stiffness and resistance of the ground floor determines the seismic behavior of the building. The building is expected to behave as "pilotis" type and to suffer from severe damages in the columns of the ground floor (soft floor). Reinforced concrete buildings with first floor irregularities studied thoroughly by Favvata et al. [1], have showed the increase of the demand for interstory drift at the ground floor. The assessment of the seismic behavior of the building will be carried out using nonlinear methods, which are pushover and time-history analyses.

Having assessed the building, which revealed the weaknesses of the structure, the decision to intervene has been made. The interventions were made to the building without considering the damages from the earthquakes. The purpose was to balance the structural weaknesses with the interventions. Among various alternatives [2], the intervention will take place firstly with the implementation of base isolation systems and afterwards with the implementation of metal braces. The two methods are based on different principles as the base isolation systems aim to isolate the superstructure from the ground motions and to decrease the seismic demand of the superstructure $[3,4]$ and the metal braces aim to increase the strength and the stiffness of the structure [5].

As concerns the base isolation system, two types of bearings have been studied, Lead Rubber Bearings and Friction Pendulum Systems [6]. A significant amount of both past and recent research has focused on the use of elastomeric and friction bearings [7, 8].The implementation of base isolation systems is expected to increase the fundamental period of the structure and therefore decrease the seismic demand for the structure. Moreover, it is expected that the horizontal displacements will be taken over by the isolation systems and the structure will move as a rigid body without any additional stresses.

As concerns the metal braces, their section has been chosen so that the braces equate the lack of stiffness in the "soft" floor of the building. The implementation of metal braces restricted to the open ground floor is expected to increase the stiffness and the strength of the ground floor and as a result to improve the seismic behavior of the entire building [5].

Finally, conclusions are drawn regarding the effectiveness of the proposed strategies. The seismic performance of the building, before and after retrofitting is evaluated according to the provisions of EC8 Part-3 [9] and the Greek Retrofitting Code [10].

\section{BUILDING DESCRIPTION}

The under study building is located on the island of Cephalonia. It is situated at the beachfront, approximately 100m from the sea. The construction of the building took place in early 1980 and it was used as a residence. It was built according to the Greek Royal Decree of 1959 [11].

The construction is a two-storey RC building without a basement. The ground plan of the building is rectangular and its surface is reduced to the first floor. The ground floor has a height of $3.30 \mathrm{~m}$ whereas the first floor a height of $3.00 \mathrm{~m}$. The structural model of the building is regular in plan as it consists of parallel frames arranged in a dense and symmetrical grid of 
columns but it is non regular in elevation as there are no infill walls located in the ground floor. Consequently the building is expected to response as a "pilotis" type building.

In Figures 1, 2 and 3, a schematic presentation of the structure is displayed. It shows the plan of both floors and the faces of the building. The area of the ground floor is hatched with diagonal lines and the area of the upper floor is located between the infill walls. It also shows the location of the infill walls that have been taken into consideration for the structural model. The beams are shown with dashed lines. The columns which do not continue in the upper floor do not have a solid hatch.

The structural system is made of reinforced concrete. The material types for the model are concrete B225 ( $\left.f_{c k}=16 \mathrm{MPa}\right)$ and rebar steel StIII $\left(\mathrm{f}_{\mathrm{yk}}=420 \mathrm{MPa}\right)$. The plates are $18 \mathrm{~cm}$ thick, horizontal and at the same level. The beams of the building are $50 \times 25 \mathrm{~cm}$ and the columns are 50x $25 \mathrm{~cm}$. The columns confinement bars are not anchored properly, so they do not contribute to the ductility and they are not included in the model. All columns are considered to be fully supported to the ground, at the soil level. The data concerning the column reinforcement have been collected from field investigation and they are presented in Table 1. The beam reinforcement has been calculated according to the Greek Royal Decree [11].

The data of the infill walls are simulated according to common practice in the island, where the infill walls usually have a considerably high resistance. The infill walls are considered to be $25 \mathrm{~cm}$ thick and to be built with clay hollow bricks with dimensions 250x250x240mm and compression strength of 10MPa and with M5 mortar.

\begin{tabular}{cc}
\hline Columns & Reinforcement \\
\hline For columns $0.26 \mathrm{mx} 0.50 \mathrm{~m}$ & $8 \Phi 20+4 \Phi 16$ \\
For columns $0.50 \mathrm{mx} 0.26 \mathrm{~m}$ & $18 \Phi 18$ \\
\hline
\end{tabular}

Table 1: Reinforcement of the columns

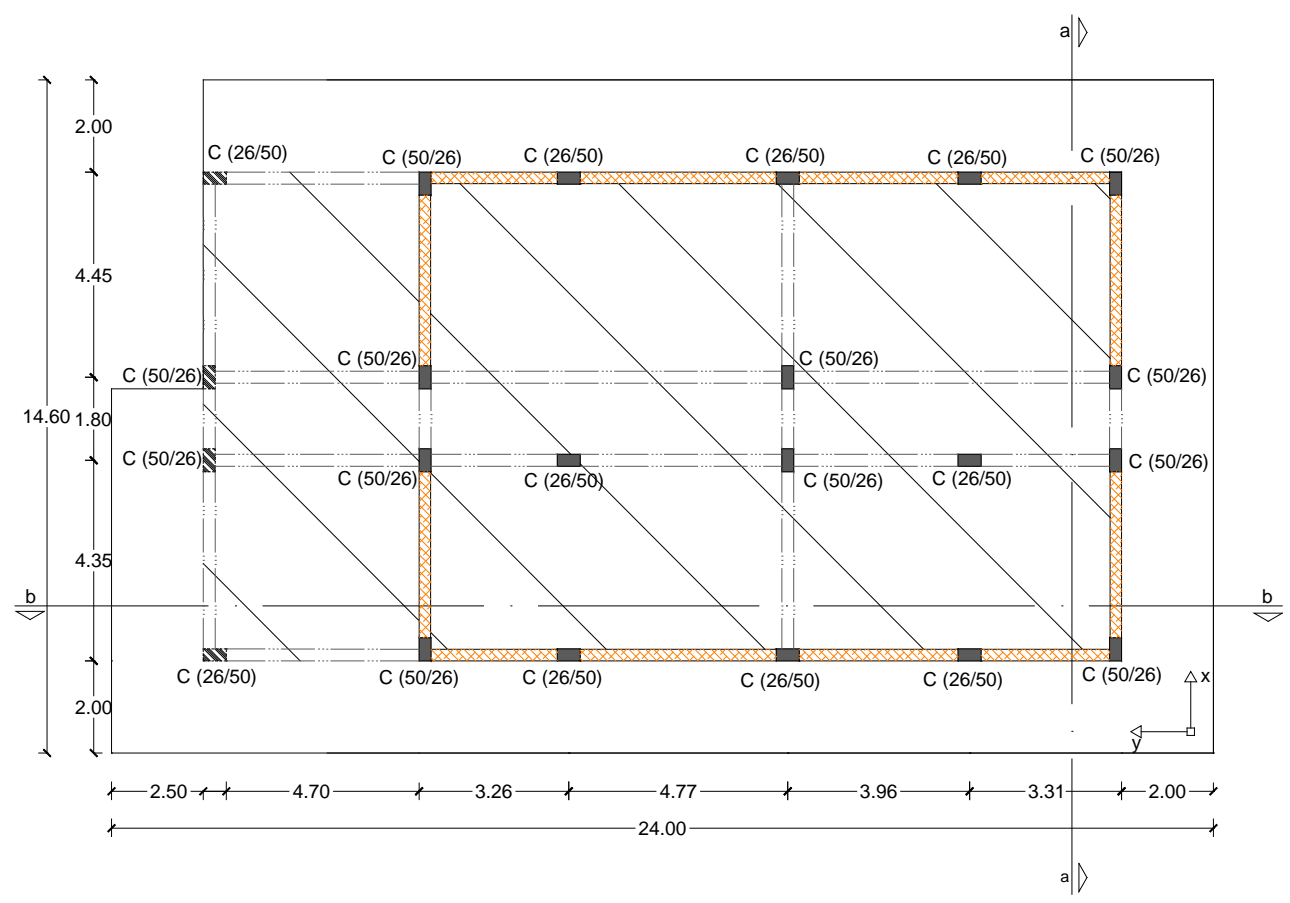

Figure 1: Schematic Plan of the Floors 


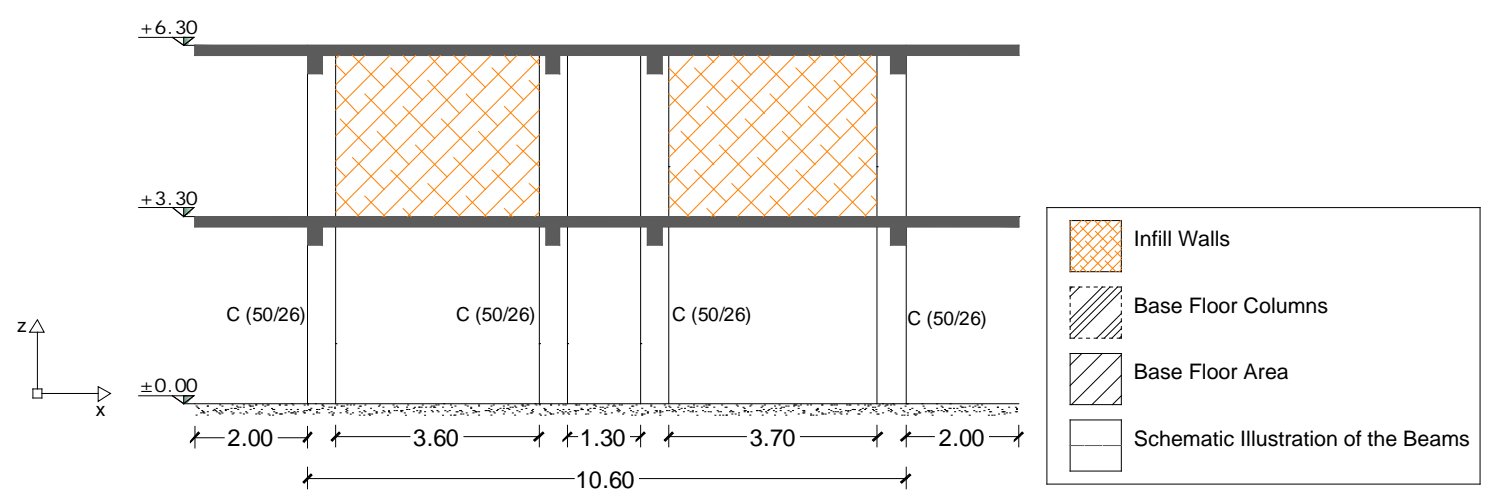

Figure 2: Architectural Section a-a

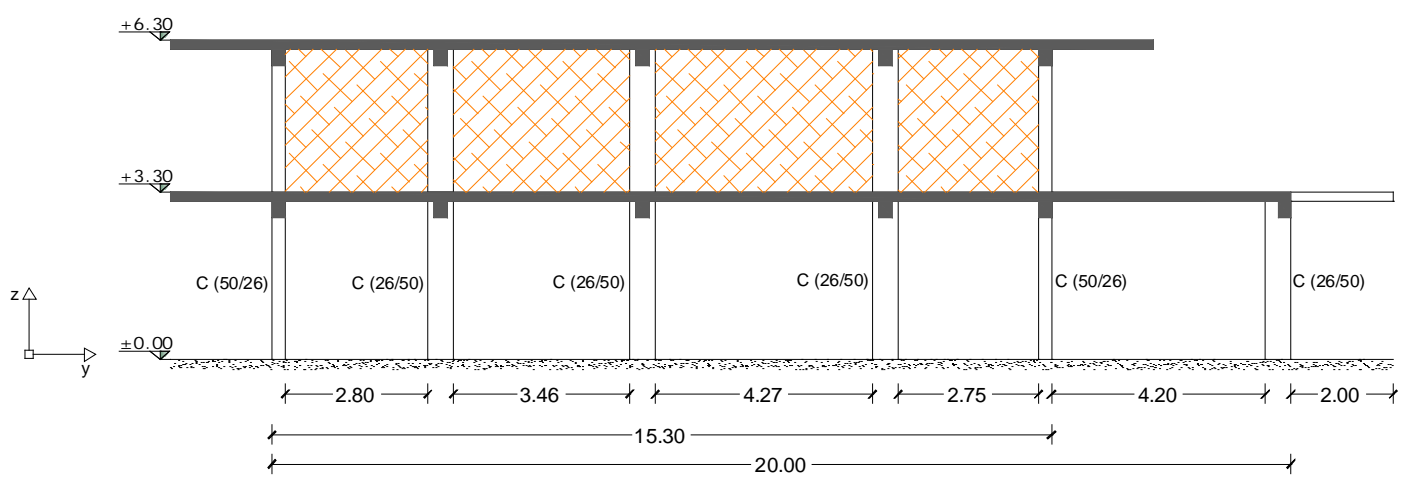

Figure 3: Architectural Section b-b

\section{SEISMIC ACTIONS}

The earthquake that occurred on the island of Cephalonia on January 26th 2014 and specifically the recorded accelerograms in the Argostoli station were used as the main seismic action. The epicenter of the earthquake was at the southwestern coasts of Cephalonia, about 9 $\mathrm{km}$ southwest of the Lixuri town. Its focal depth was $21 \mathrm{~km}$ and its magnitude M6.1.The actual accelerograms of the earthquake in $\mathrm{x}$ and $\mathrm{y}$ directions were used in the analysis, as it is intended to verify the actual behavior of the building. The vertical component of the earthquake was not used as it is not required according to EC8. The accelerograms of the earthquake and the acceleration spectrum are presented in Figures 4 and 5. The east to west axis is parallel to the $\mathrm{x}-$ axis of the building and the north to south axis to the $\mathrm{y}$-axis.
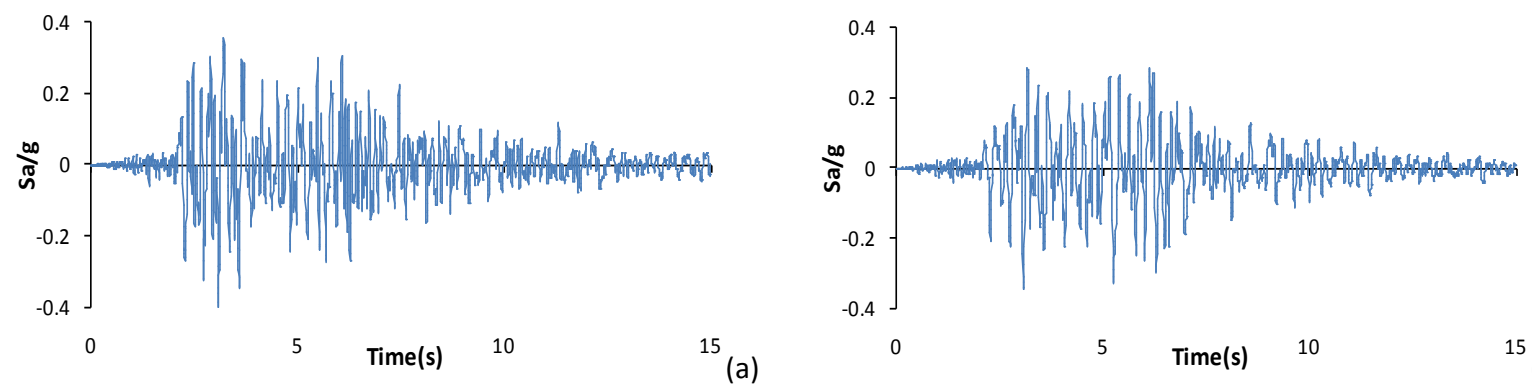

Figure 4: Accelerograms in (a) north to south direction, (b) east to west direction 


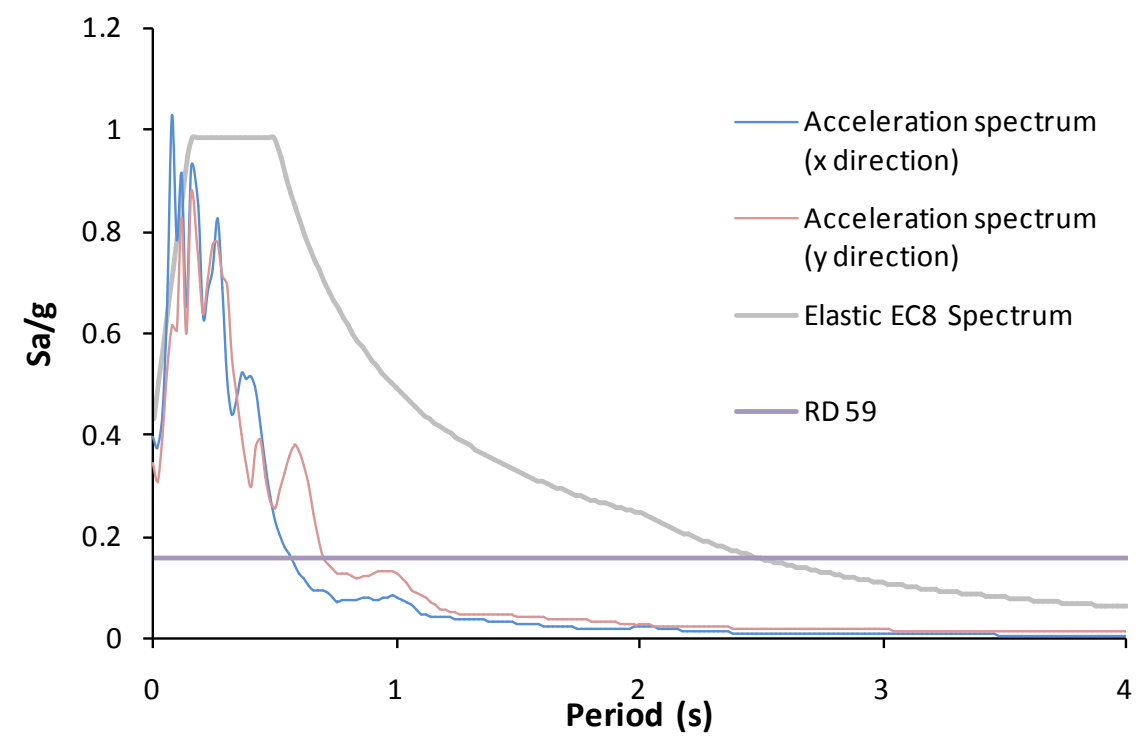

Figure 5: Acceleration Spectrum

\section{DAMAGE DISTRIBUTION AFTER THE EARTHQUAKE}

As it has been mentioned, the studied building is expected to behave as a "pilotis" type building. The lack of infill walls in the ground floor creates asymmetry in the distribution of stiffness in elevation. As a result, the application of the seismic force causes torsion to the vertical axis and leads to the development of a "soft" floor mechanism. Specifically, the failure is performed with the creation of plastic hinges at the top and base of the columns of the "soft" floor. This mechanism leads to the concentration of all movements in the ground floor, to the development of P-Delta effects and eventually to total or partial collapse.

After conducting field investigation, the type and extent of the present structural damage agrees with the above description. The majority of the ground floor columns have been heavily damaged. Plastic hinges have been created at the top and the base of those columns. The upper floor has reacted as a rigid body with the structural members and the infill walls behaving linearly. Figure 6 is representative of the building situation.

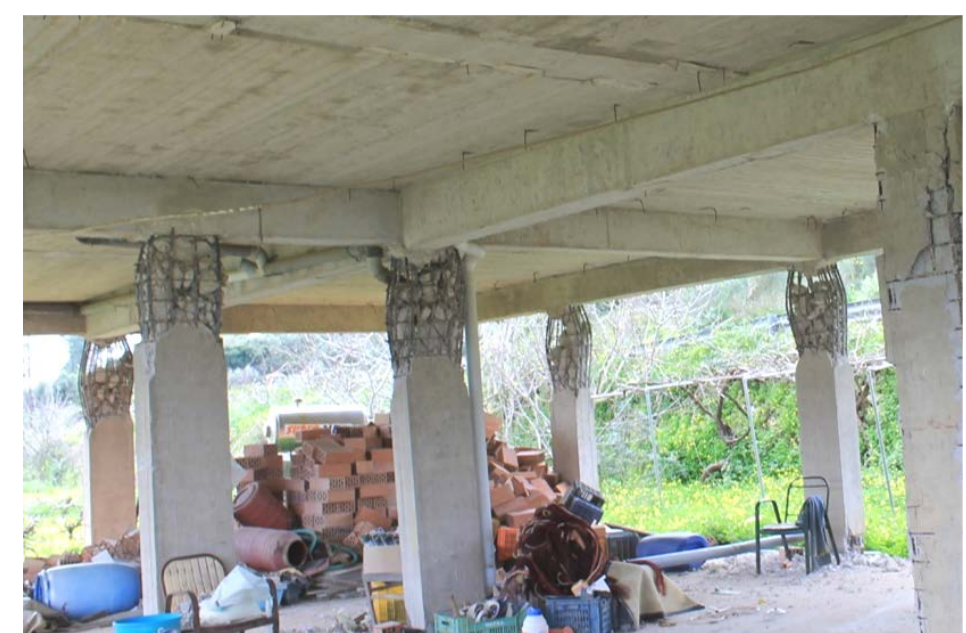

(a)

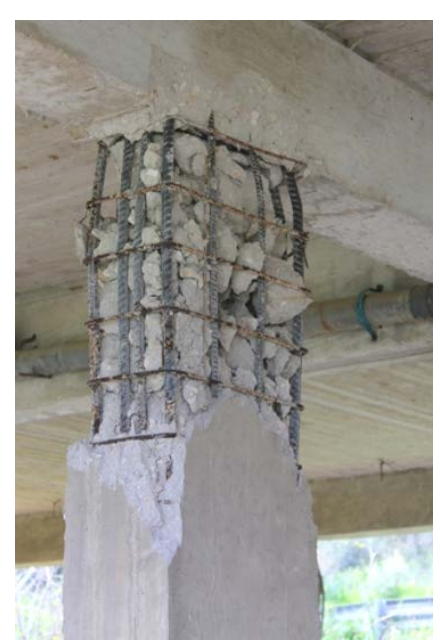

(b)

Figure 6: (a) Photograph of the ground floor, (b) Close up to a damaged column 


\section{SIMULATION OF THE STRUCTURAL SYSTEM}

The building is simulated as a 3D model which includes all the members that contribute to the seismic behavior of the building (beams, columns and infill walls). The nonlinear behavior of the frame members is represented with the assignment of plastic hinges in the critical sections of the members.

\subsection{Simulation of the structural members}

As regards the beams, the model that is used represents the uniaxial bending of the beam. The used model defines the relation between the bending moment and the rotation of the section. The plasticity is concentrated at the ends of the beams. The hysteresis of the model is determined according to the Takeda hysteresis model [12]. A different type of element is adopted in order to model the columns. This model correlates the biaxial bending with axial force using the fiber model which distributes the plasticity along the column length [13, 14].

\subsection{Simulation of the infill walls}

The model of equivalent diagonal strut is used in order to simulate the infill walls. It should be noticed that the infill walls are simulated in such a way so that they exhibit axial response only. The diagonal bar is pinned in the nodes of the frame. The dimension of the diagonal bar and the stress - deformation diagram (Figure 7) are calculated according to the Greek Retrofitting Code [10].

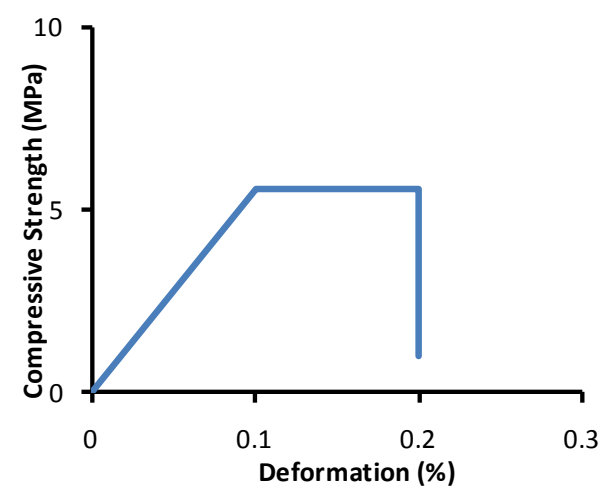

Figure 7: Stress - Deformation Diagram of infill walls

\section{ASSESSMENT ANALYSES}

\subsection{Modal Analysis}

Modal analysis is a way to have a better understanding of the behavior of a building. Moreover the periods of the two first modes are necessary clues for the nonlinear dynamic analysis. The results of the modal analysis are shown in Table 2.

\begin{tabular}{cccc}
\hline Mode & Movement & Period (s) & Mass Participation Ratios \\
\hline 1 & translational $x$ axis & 0.38 & 0.828 \\
2 & translational y axis & 0.374 & 0.957 \\
3 & rotational & 0.308 & 0.605 \\
\hline
\end{tabular}

Table 2: Modal Analysis Results 


\subsection{Nonlinear analyses}

Nonlinear analyses are primarily used for the assessment of existing buildings. Those analysis methods take into account the inelastic response of the used materials and calculate the nonlinear behavior of the member section and therefore the behavior of the member and the whole structure. The nonlinear analyses approach the real behavior of a building in an accurate way. The Greek Retrofitting Code [10] defines two types of nonlinear analysis, pushover analysis and time history analysis.

\subsubsection{Pushover analysis}

Pushover analysis approaches, by sequential analyses, the nonlinear behavior of the structural system under different distribution of lateral forces. Reinforced concrete frame structure evaluation using nonlinear static analyses has been studied by Karayannis and Favvata [15]. The control of the structure is carried out in the step (performance point) during which the capacity of the building meets the demand of the regulations (in this work the response spectrum of EC8 Part-1 [16]). In this step, the deformations of the critical sections are compared with the defined by the regulations deformations in terms of plastic rotation. The result of the comparison is the expected by the regulation behavior of the critical sections (linear or nonlinear response, performance requirements).

Two different distributions of lateral forces are used. The first is a triangular distribution of the lateral forces and the second a uniform distribution of the lateral forces. The structure is analyzed for combination of the lateral forces which are parallel to the two main directions. These combinations are $\mathrm{x}+0.3 \mathrm{y}$ and $\mathrm{y}+0.3 \mathrm{x}$.

The results for the structure that is being studied are shown below. Figure 8 presents the local nonlinear behavior of the members of the building in terms of plastic rotational hinge requirement, based on the limit state of the critical sections. The yielded results correspond to the maximum limit state that has been reached between the triangular and the uniform distribution of the lateral forces for both combinations of the lateral forces.

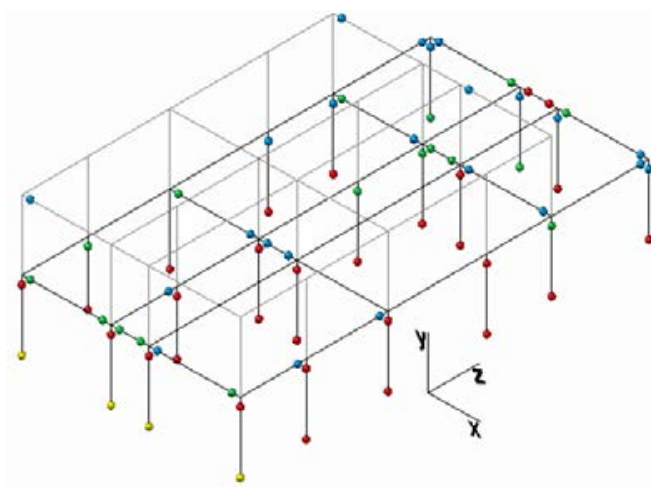

(a)

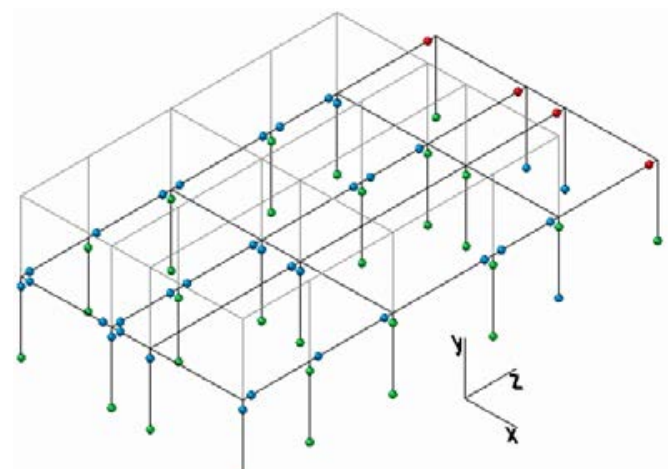

Legend $-0-\mathrm{DL} \rightarrow-\mathrm{SD} \rightarrow-\mathrm{NC} \rightarrow-$ COLLAPSE

(b)

Figure 8: Damage Distribution (a) for combination $x+0.3 y$, (b) for combination $y+0.3 x$

As it is shown in Figure 8, the majority of the critical sections of the columns and beams of the ground floor behaved nonlinearly, while the majority of the upper floor members responded linearly. As regards the combination of the lateral forces $x+0.3 y$ the rotation requirement is larger, as the Near Collapse (NC) limit state is reached while, as regards the combination $\mathrm{y}+0.3 \mathrm{x}$, the Significant Damage $(S D)$ limit state is reached. 

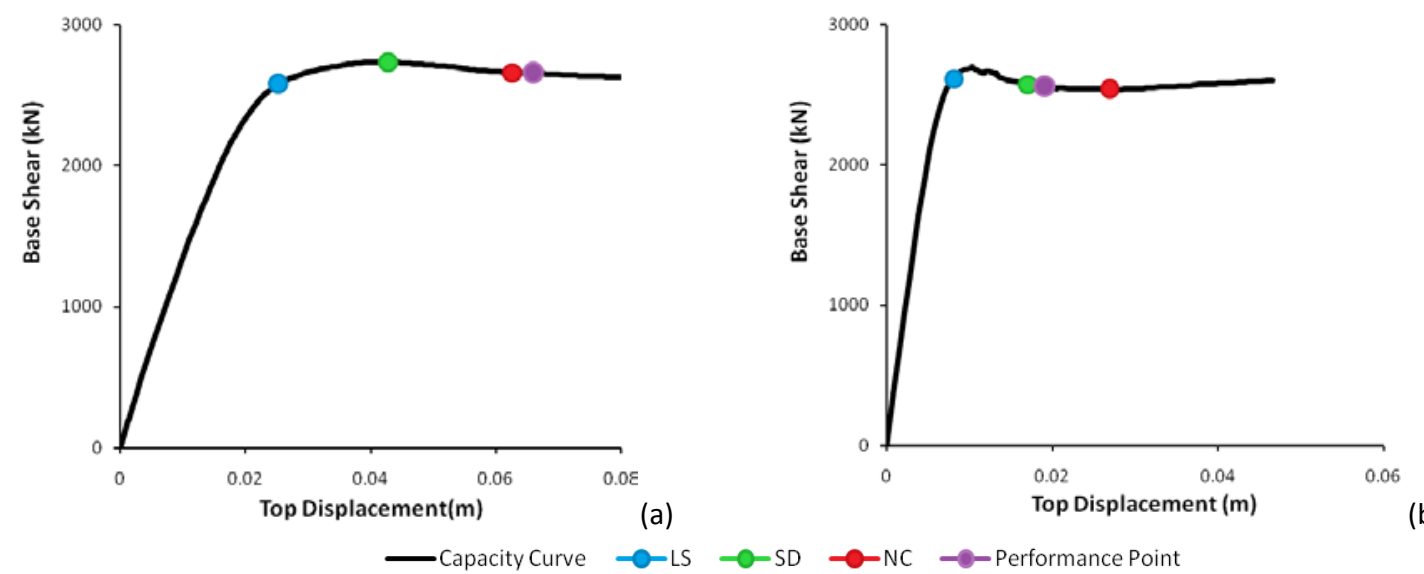

Figure 9: Capacity Curves (a) for combination $x+0.3 y$, (b) for combination $y+0.3 x$

The limit state of the structure can also be observed by the capacity curves of the structure (Figure 9). The capacity curves are almost identical for both distributions of the lateral force. As it is shown by the diagrams, for the combination of the lateral forces $x+0.3 y$, the performance point exceeds the Near Collapse (NC) limit state with top displacement equal to $0.067 \mathrm{~m}$ and for the combination $\mathrm{y}+0.3 \mathrm{x}$, the performance point exceeds the Significant Damage (SD) limit state with top displacement equal to $0.062 \mathrm{~m}$.

In Figure 10, the storey drift for both combinations of the lateral force is presented. As it is obvious, the displacement of the down floor is significantly higher than that of the upper floor. Specifically, as regards the combination $x+0.3 y$, the storey drift of the down floor is $2.23 \%$, while the storey drift of the upper floor is $0.06 \%$. As regards, the combination $y+0.3 x$, the storey drift of the down floor is $2.19 \%$, while the storey drift of the upper floor is $0.02 \%$.
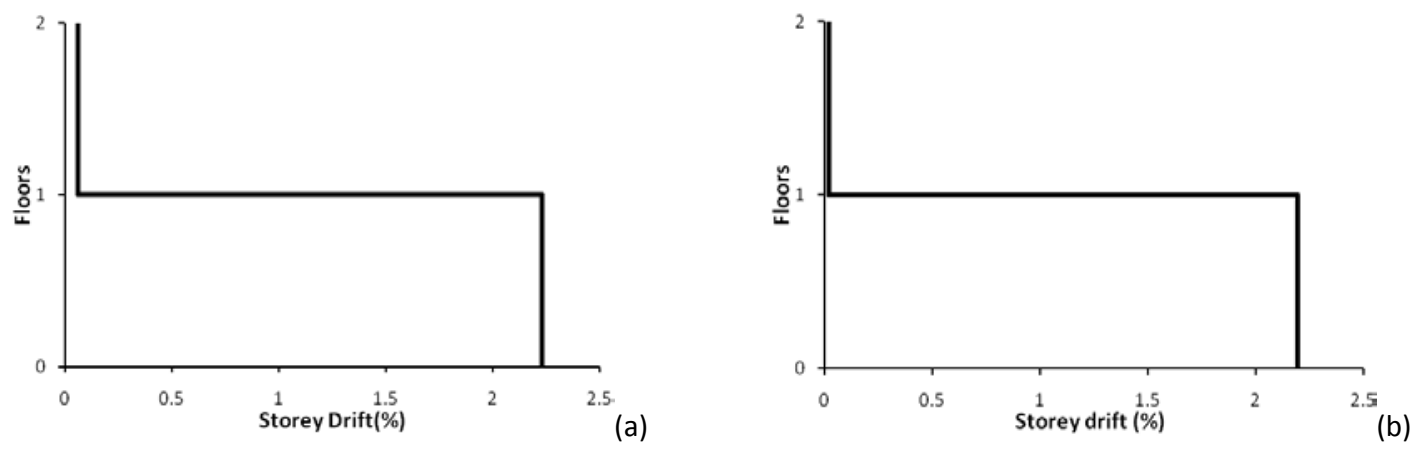

Figure 10: Storey Drift Diagram (a) for combination $x+0.3 y$, (b) for combination $y+0.3 x$

\subsubsection{Time history analysis}

In time history analysis, a sequential solving of the dynamic problem for every time step of an earthquake is performed. The time history analysis is the most accurate method of analysis, but it is difficult to use because of the great computational cost, the difficulty of processing the huge amount of data and the need of carefully choosing the right accelerograms. The structure is analyzed for combination of the seismic forces parallel to the two main directions. These combinations are $\mathrm{x}+0.3 \mathrm{y}$ and $\mathrm{y}+0.3 \mathrm{x}$.

The results for the structure that is being studied are shown below. Figure 11 presents the local nonlinear behavior of the building members in terms of plastic rotational hinge requirement based on the limit state of the critical sections. 


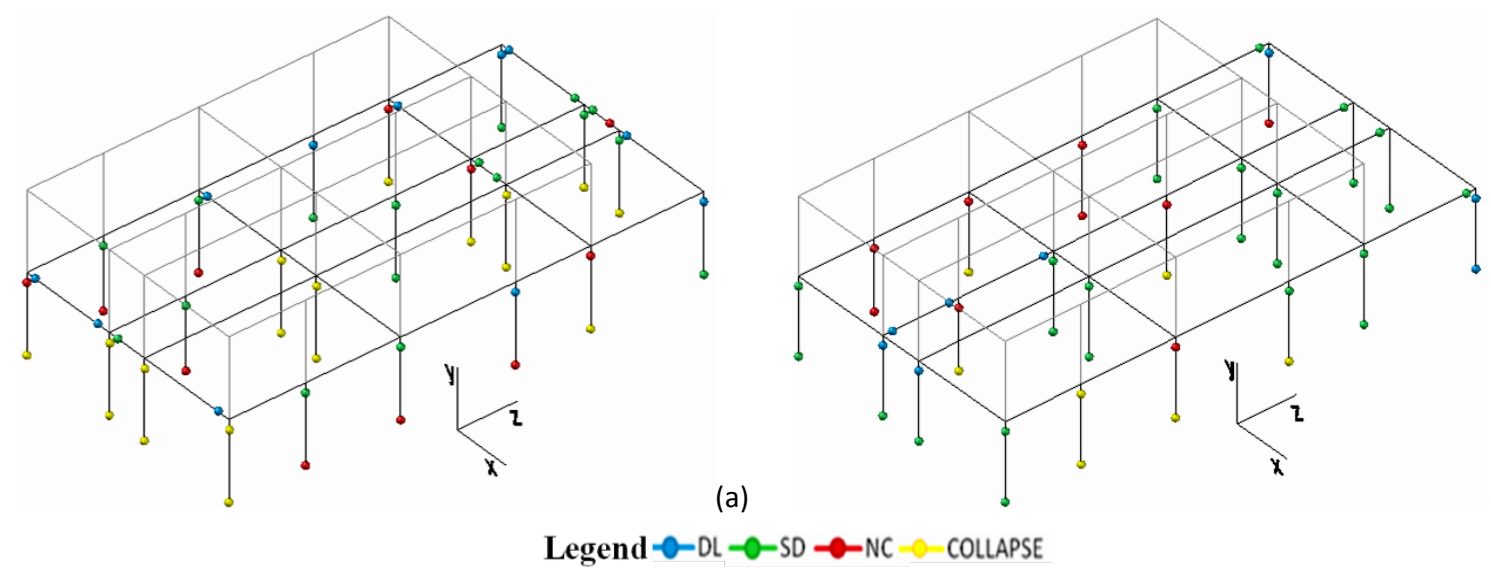

(b)

Figure 11: Damage Distribution (a) for combination $x+0.3 y$, (b) for combination $y+0.3 x$

As it is shown in Figure 11, the majority of the critical sections of the columns and beams of the ground floor responded inelastically, while the structural members of the upper floor responded elastically. The majority of the sections either reaches or exceeds the Near Collapse (NC) limit state for both combinations.
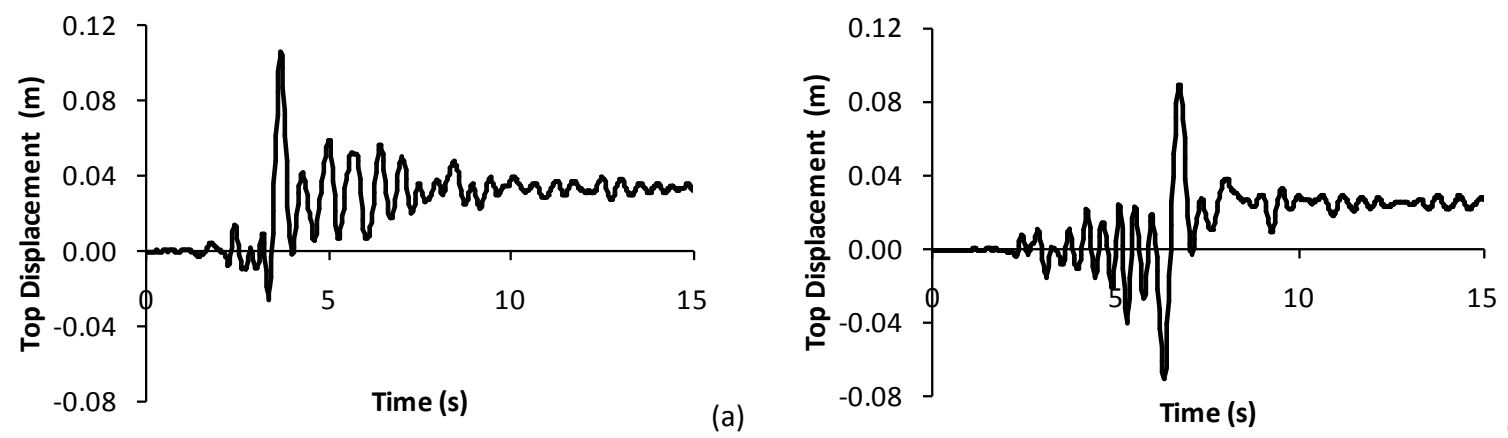

(b)

Figure 12: Top Displacement (a) for combination $\mathrm{x}+0.3 \mathrm{y}$, (b) for combination $\mathrm{y}+0.3 \mathrm{x}$

In Figure 12, the top displacement of the building per time is shown. The maximum top displacement for the combination $\mathrm{x}+0.3 \mathrm{y}$ is $0.106 \mathrm{~m}$ and for the combination $\mathrm{y}+0.3 \mathrm{x}$ is $0.089 \mathrm{~m}$. For both combinations, at the earthquake end the top displacement of the building is different to zero (in combination $\mathrm{x}+0.3 \mathrm{y}$ is $0.032 \mathrm{~m}$ and in combination $\mathrm{y}+0.3 \mathrm{x}$ is $0.027 \mathrm{~m}$ ). The reason for that is that the columns of the ground floor are permanently deformed.

In addition, in Figure 13, the storey drift of the building is presented. It can be observed that the relative displacement of the upper floor is considerably less than the displacement of the ground floor. Specifically, as regards the combination $x+0.3 y$, the storey drift of the ground floor is $3.13 \%$ while the storey drift of the upper floor is $0.03 \%$. As regards the combination $y+0.3 \mathrm{x}$, the storey drift of the ground floor is $2.72 \%$ while the storey drift of the upper floor is $0.03 \%$. 

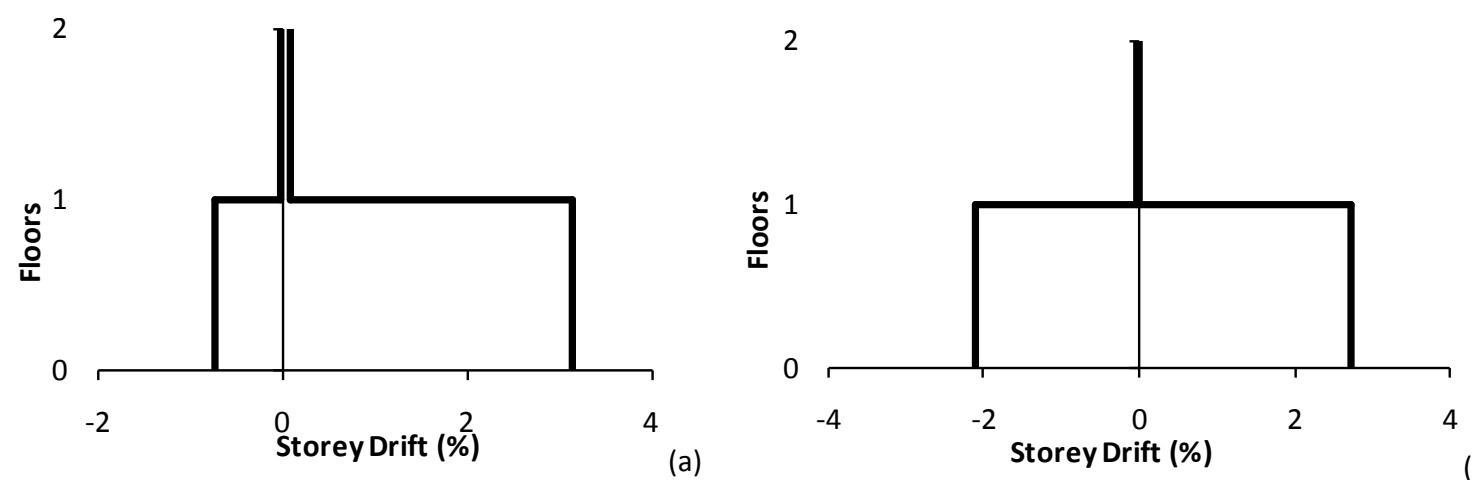

Figure 13: Storey Drift Diagram (a) for combination $\mathrm{x}+0.3 \mathrm{y}$, (b) for combination $\mathrm{y}+0.3 \mathrm{x}$

\section{BASE ISOLATION}

The next phase of the paper is the retrofitting of the existing structure. Firstly, it is intended to reduce the seismic demand for the building with the use of seismic isolation systems. The reduction of the seismic response of the lateral - force resisting system is obtained by increasing the fundamental period of the seismically isolated structure and the damping. As a result, the isolators take over a great percentage of the horizontal displacement. The structure moves like a rigid solid body and does not take over tension from the seismic forces. In this work, two types of isolators have been used, Lead Rubber Bearings (LRB) and Friction Pendulum Systems (FPS).

\subsection{Simulation of base isolation systems}

According to the Greek Retrofitting Code [10] and EC8 Part-3 [9], the hysteresis diagram of an LRB and an FPS can be modeled as bilinear. In Figures 14 and 16 the typical force displacement diagrams for an LRB and an FPS is presented, respectively. In this work, the bearings are designed according to the simplified linear analysis method (EC8 Part-1).

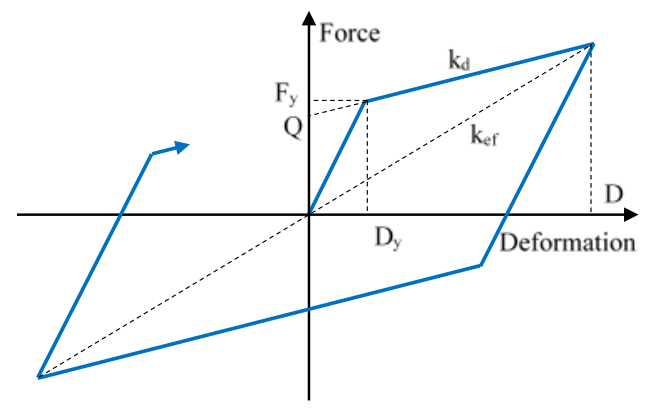

Figure 14: Bilinear Force - Deformation Diagram of LRB

The behavior of an LRB can be defined throughout the yield point load of the lead core $\left(\mathrm{F}_{\mathrm{y}}\right)$, the lead core contribution to the horizontal stiffness $\left(\mathrm{K}_{\text {lead}}\right)$ and the elastomer contribution to the horizontal stiffness $\left(\mathrm{K}_{\mathrm{r}}\right)$. The implemented LRB bearing has a diameter of $350 \mathrm{~mm}$, elastomer thickness of $112 \mathrm{~mm}$ and the effective damping takes a value $b_{\text {eff }}=28 \%$. The shear modulus of the elastomer is equal to $\mathrm{G}=0.4 \mathrm{MPa}$. The analysis model is based on the hysteresis model which was suggested by Wen [17] and Park et al. [18] (Figure 15). 


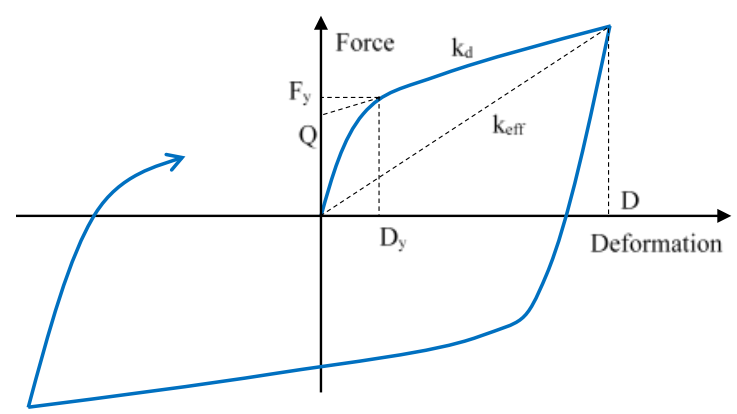

Figure 15: Hysteresis Model of LRB

The response of friction pendulum systems can be described using the radius of curvature $(\mathrm{R})$, the coefficient of friction $(\mu)$ and the effective vertical load (V). The implemented FPS bearing has radius of curvature $2.5 \mathrm{~m}$, coefficient of friction 0.055 and effective vertical load $560 \mathrm{kN}$. The analysis model is based on the hysteresis model recommended for base isolation analysis suggested by Nagarajaiah et al. [19] and on the sliding behavior suggested by Zayas et al. [20].

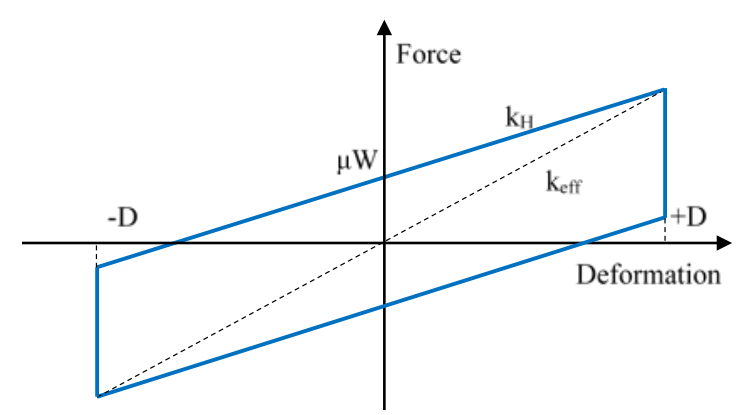

Figure 16: Bilinear Force - Deformation Diagram of FPS

\subsection{Results}

\begin{tabular}{|c|c|c|c|c|}
\hline Mode & Movement & $\begin{array}{c}\text { Initial } \\
\text { Period (s) }\end{array}$ & $\begin{array}{c}\text { Period } \\
\text { LRB (s) }\end{array}$ & $\begin{array}{l}\text { Period } \\
\text { FPS(s) }\end{array}$ \\
\hline 1 & $\begin{array}{c}\text { translational } \\
\mathrm{x} \text { axis }\end{array}$ & 0.38 & 1.936 & 3.582 \\
\hline 2 & $\begin{array}{c}\text { translational } \\
\text { y axis }\end{array}$ & 0.374 & 1.91 & 3.538 \\
\hline
\end{tabular}

Table 3: Modal Analysis Results

The implementation of the base isolation systems has successfully increased the fundamental period (Table 3). The period of the first mode increased from 0.38s to 1.936s with the use of LRB. With the use of FPS the period of the first mode increased from 0.38 s to 3.58s. The structural members and the infill walls responded linearly for both types of bearings. The hysteresis behavior of the bearings is shown in Figure 17. 

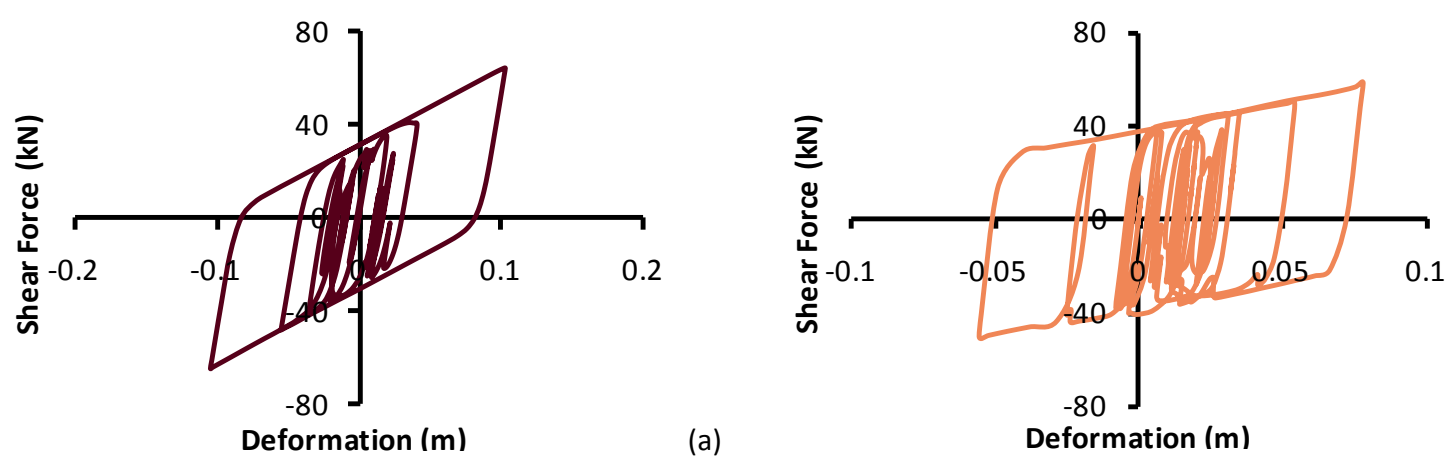

Figure 17: Hysteresis behavior of (a) LRB, (b) FPS

In Figure 18, the relative displacement between the top and the base of the structure is shown. This Diagram represents the behavior of the structure in three different conditions, the initial (without any intervention) and the intervention with each base isolation system (LRB and FPS). In the initial stage, the relative displacement between the top and the base of the building is significantly larger than the displacement which corresponds to the intervention with the base isolation systems. In the first case, the ground floor columns deform and because of that the maximum relative displacement is $0.106 \mathrm{~m}$. At the same time, after the base isolation intervention, the horizontal displacement is taken over by the bearings and consequently the member deformations are approximately 10 times less and the maximum relative displacement is $0.017 \mathrm{~m}$ for the FPS and $0.015 \mathrm{~m}$ for the LRB. It is also observed that after the intervention with base isolation systems, there is no permanent displacement. Before the intervention the permanent displacement of the structure was for both combinations close to $0.03 \mathrm{~m}$.

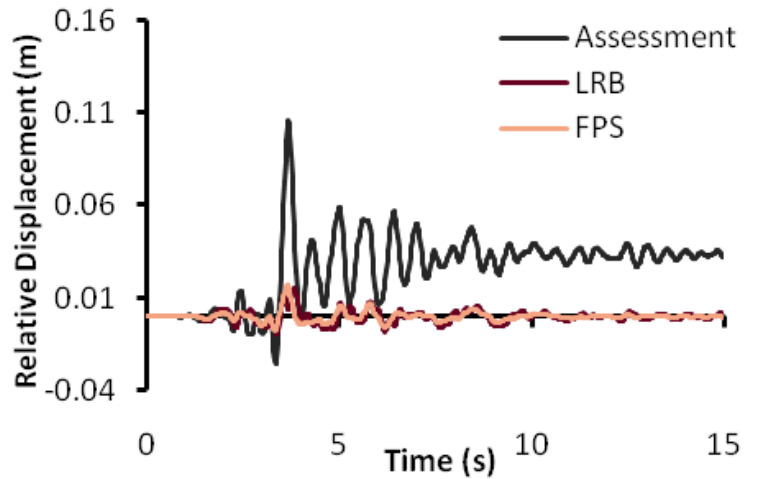

(a)

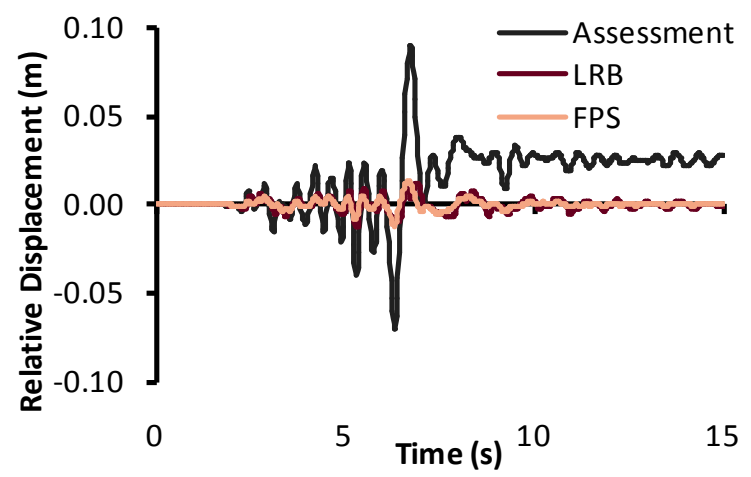

(b)

Figure 18: Top to Base Relative Displacement (a) for combination $\mathrm{x}+0.3 \mathrm{y}$, (b) for combination $\mathrm{y}+0.3 \mathrm{x}$

In Figure 19, the storey drift for the initial condition and the base isolation intervention (LRB and FPS) is shown. The storey drift is significantly decreased with the use of base isolation systems. Specifically, for the combination $x+0.3 y$ before the intervention, the maximum storey drift is $3.13 \%$ while after the intervention with LRB, the maximum storey drift is $0.43 \%$ and with FPS it is $0.48 \%$. For the combination $y+0.3 x$ before the intervention, the maximum storey drift is $2.72 \%$ while after the intervention with LRB, the maximum storey drift is $0.36 \%$ and with FPS it is $0.37 \%$. 


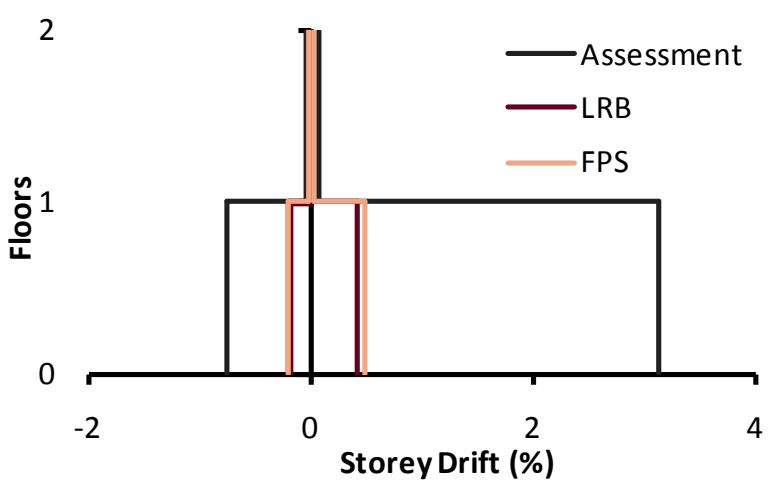

(a)

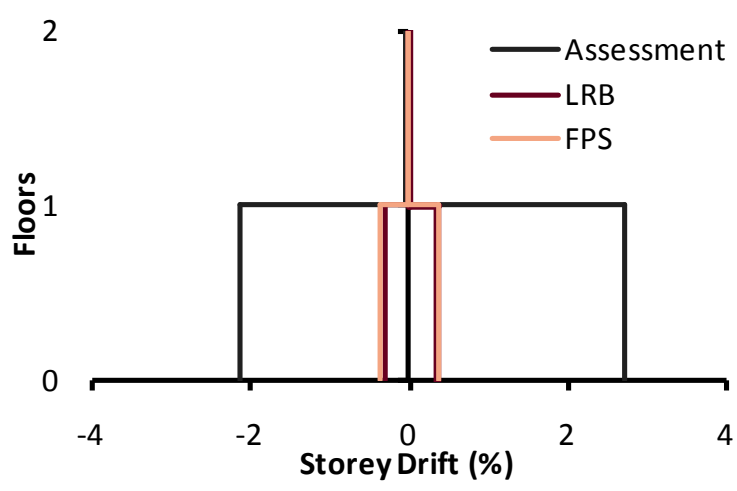

(b)

Figure 19: Storey Drift Diagram (a) for combination $x+0.3 y$, (b) for combination $y+0.3 x$

In Figure 20, the shear distribution to the floors for the initial condition and the base isolation intervention (LRB and FPS) is shown. The shear distribution is significantly decreased with the use of base isolation systems. Specifically, for the combination $x+0.3 y$ before the intervention, the maximum shear force to the ground floor is near to $2900 \mathrm{kN}$ while after the intervention with LRB, the maximum shear force to the ground floor is about $1550 \mathrm{kN}$ and with FPS it is close to $1700 \mathrm{kN}$. For the combination $\mathrm{y}+0.3 \mathrm{x}$ before the intervention, the maximum shear force to the ground floor is about $1900 \mathrm{kN}$, while after the intervention with LRB the maximum shear force to the ground floor is about $550 \mathrm{kN}$ and with FPS it is close to $600 \mathrm{kN}$.

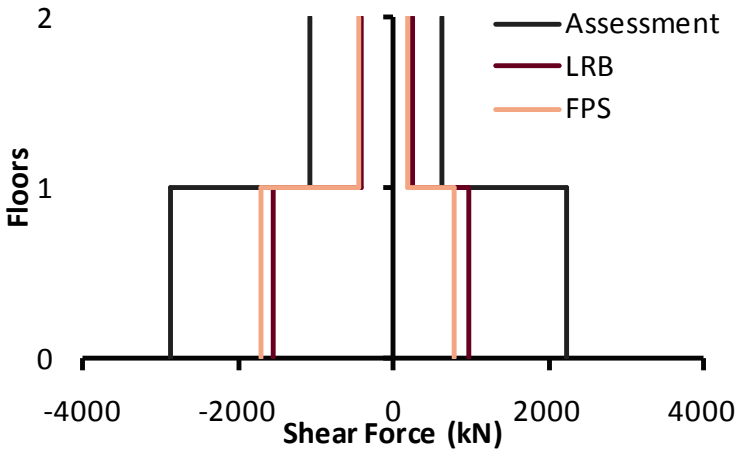

(a)

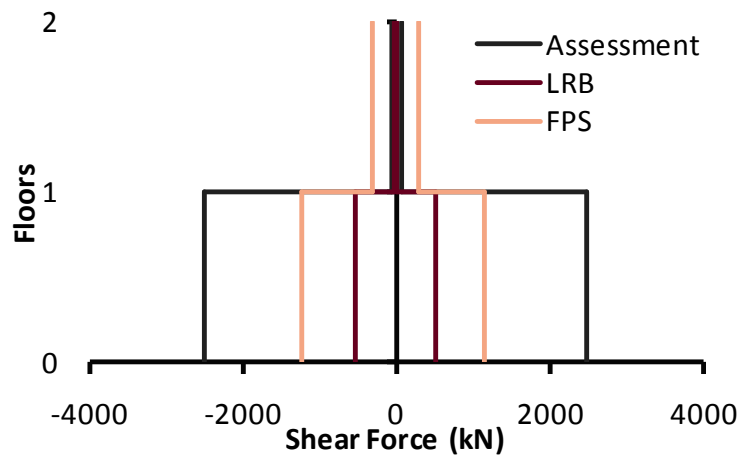

(b)

Figure 20: Shear Distribution per floor (a) for combination $x+0.3 y$, (b) for combination $y+0.3 x$

\section{METAL BRACES}

The second intervention method used is the implementation of metal braces. The metal braces with the beams and columns of the building behave as a truss. The horizontal seismic force is taken over from the diagonal bars of the formed truss (the metal braces). The brace material is chosen to be steel. Steel because of its ductility deforms significantly and observes a great amount of seismic energy.

The section of the metal braces has been chosen so that the additional stiffness to the ground floor balances the initial stiffness lack of that floor. In order to accomplish this, the chosen section is SHSH120x120x10. These braces have been chosen to be placed crosswise, with no eccentricities and pinned to the frame nodes. Moreover, the metal braces have been placed symmetrically in plan, so as not to cause torsional phenomena. 


\subsection{Simulation}

The metal braces simulation has been performed according to the Greek Retrofitting Code [10] model regarding the relation between the axial force and the axial deformation. That diagram is presented in Figure 21. The control of the braces has been performed according to the EC8 Part-3 [9] model for the axial deformation capacity of braces in compression and tension. The location of the metal braces in the building is also presented in Figure 22.

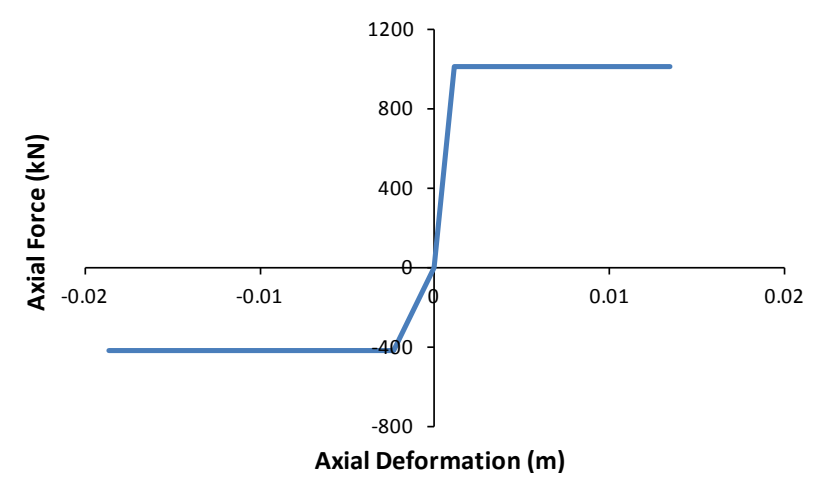

Figure 21: Force - Deformation Diagram for metal braces

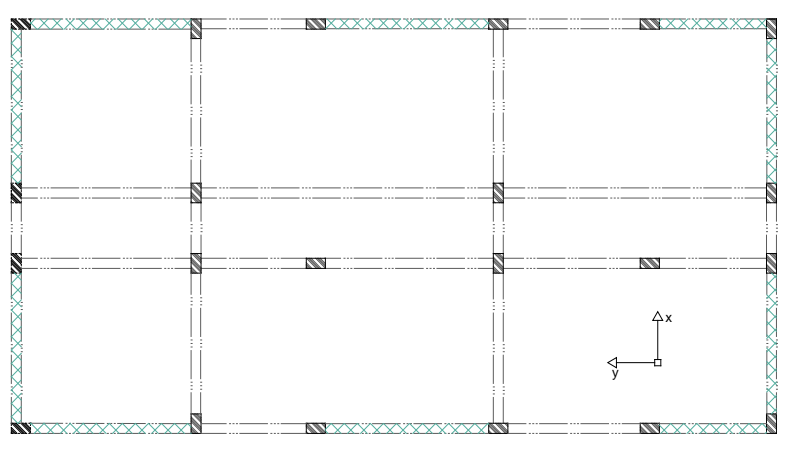

(a)

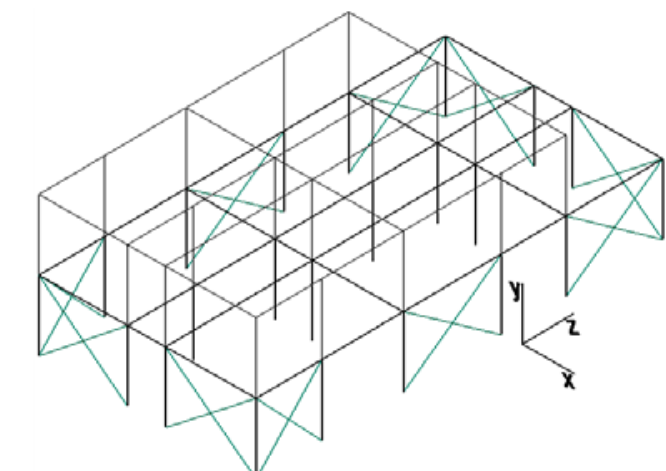

Metal Braces

Base Floor Columns Schematic Illustration of the Beams

(b)

Figure 22: Position of the implemented metal braces (a) in plan, (b) in 3D

\subsection{Modal analysis results}

\begin{tabular}{cccc}
\hline Mode & Movement & $\begin{array}{c}\text { Initial } \\
\text { Period (s) }\end{array}$ & $\begin{array}{c}\text { Period (s) } \\
\text { (Metal Braces) }\end{array}$ \\
\hline 1 & translational x axis & 0.38 & 0.267 \\
2 & translational y axis & 0.374 & 0.228 \\
3 & rotational & 0.308 & 0.174 \\
\hline
\end{tabular}

Table 4: Modal Analysis Results

The implementation of the metal braces has increased the stiffness of the building and decreased the fundamental period of the building. The period of the first mode has decreased from $0.38 \mathrm{~s}$ to $0.267 \mathrm{~s}$ with the implementation of metal braces. 


\subsection{Pushover analysis results}

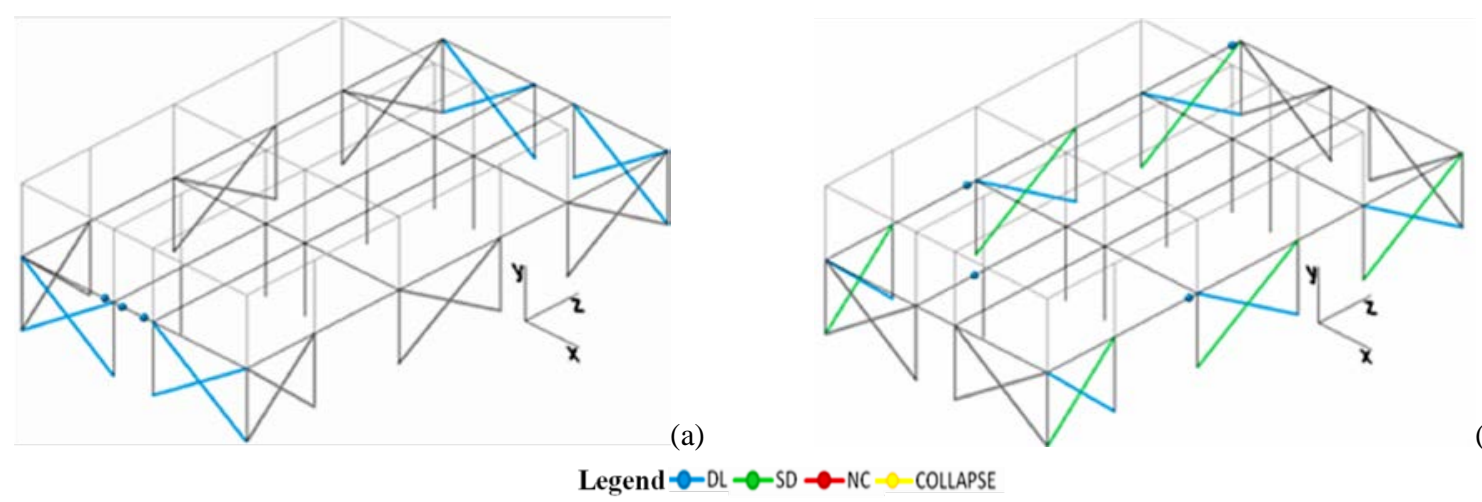

(b)

Figure 23: Damage Distribution (a) for combination $\mathrm{x}+0.3 \mathrm{y}$, (b) $\mathrm{y}+0.3 \mathrm{x}$

Figure 23 presents the local nonlinear behavior of the structural members in terms of plastic rotational hinge requirement based on the limit state of the critical sections. The results that are being shown correspond to the maximum limit state that has been reached between the triangular and the uniform distribution of the lateral forces for both combinations of the lateral forces. The majority of the structural members responded elastically.

For both combinations, increased performance requirements are observed only in a small number of beam critical sections and to the metal braces that are situated parallel to the direction of the force. For the combination $x+0.3 y$, the sections that behaved nonlinearly reached the Damage Limitation ( $D L)$ limit state, while for the combination $\mathrm{y}+0.3 \mathrm{x}$ they reached either the Damage Limitation (DL) limit state or the Significant Damage (SD) limit state. The metal braces are replaceable, so the damages that occurred to them are considered fixable. The beams are lightly damaged and can also be repaired.

Figure 24 shows a comparison between the capacity curves before and after the implementation of metal braces. The increase of stiffness and strength is obvious. The performance point after the intervention for both combinations is in the elastic part of the capacity curve. The structure behaved elastically. In Figure 25 the storey drift for the initial condition and the intervention with metal braces is shown. The storey drift is significantly decreased with the use of base isolation systems. Specifically, for the combination $x+0.3 y$ before the intervention the maximum storey drift is $2.23 \%$ while after the intervention the maximum storey drift is $0.15 \%$. For the combination $y+0.3 x$ before the intervention the maximum storey drift is $2.19 \%$ while after the intervention the maximum storey drift is $0.25 \%$.
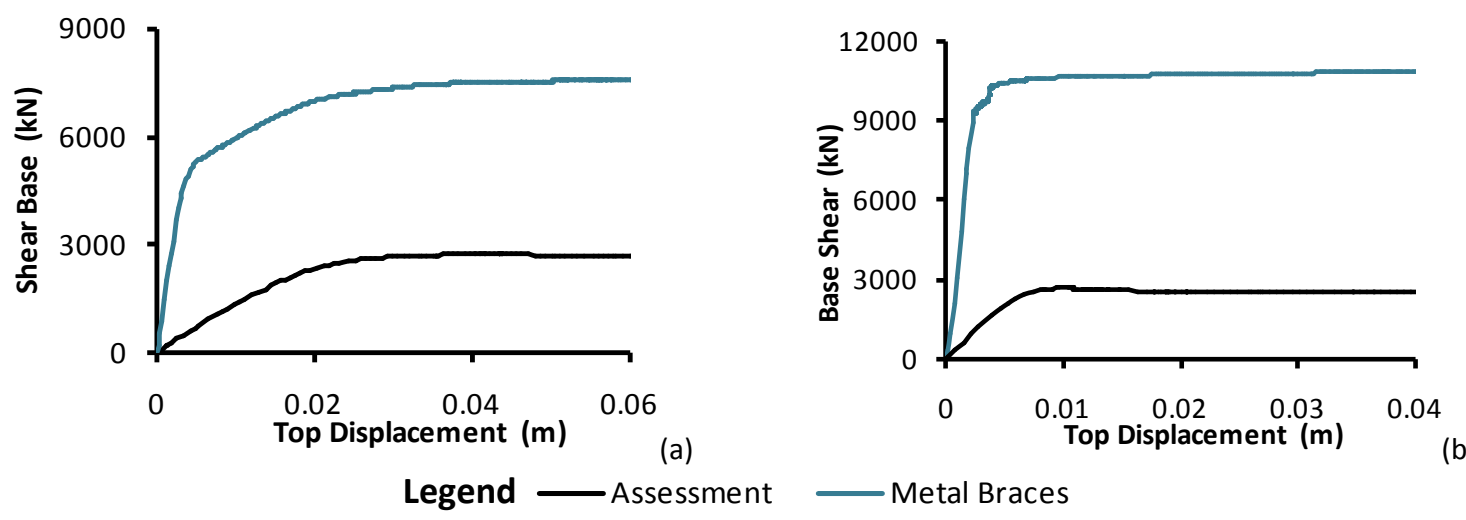

Figure 24: Capacity Curves (a) for combination $\mathrm{x}+0.3 \mathrm{y}$, (b) for combination $\mathrm{y}+0.3 \mathrm{x}$ 

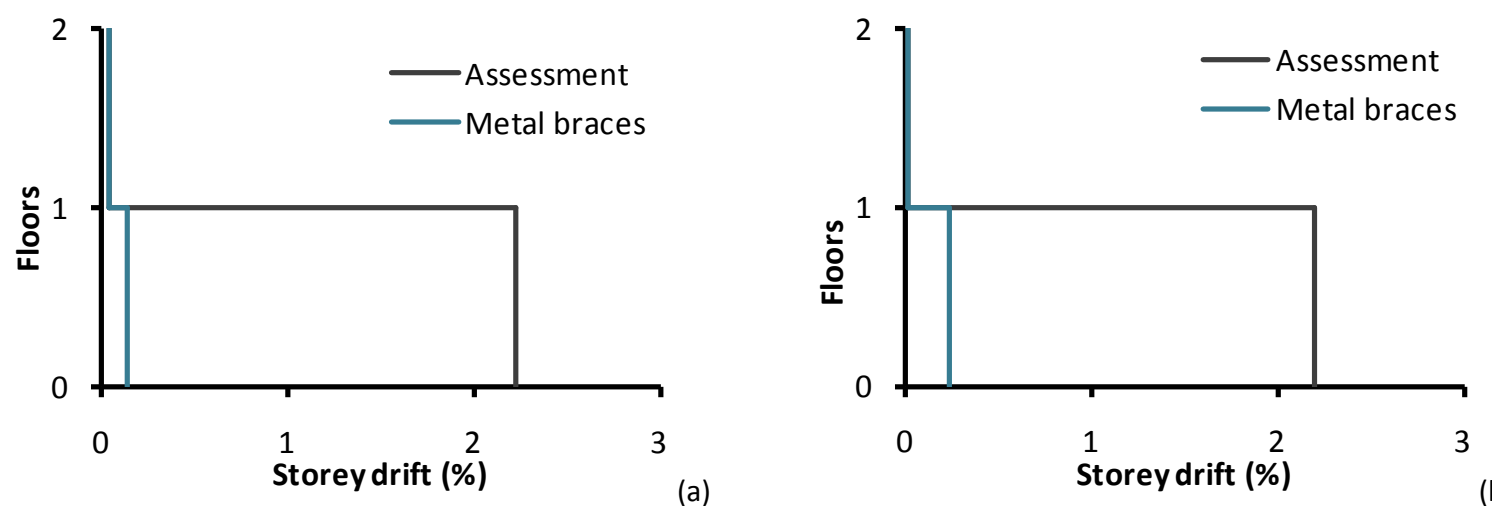

Figure 25: Storey Drift Diagram (a) for combination $\mathrm{x}+0.3 \mathrm{y}$, (b) for combination $\mathrm{y}+0.3 \mathrm{x}$

\subsection{Time history analysis results}
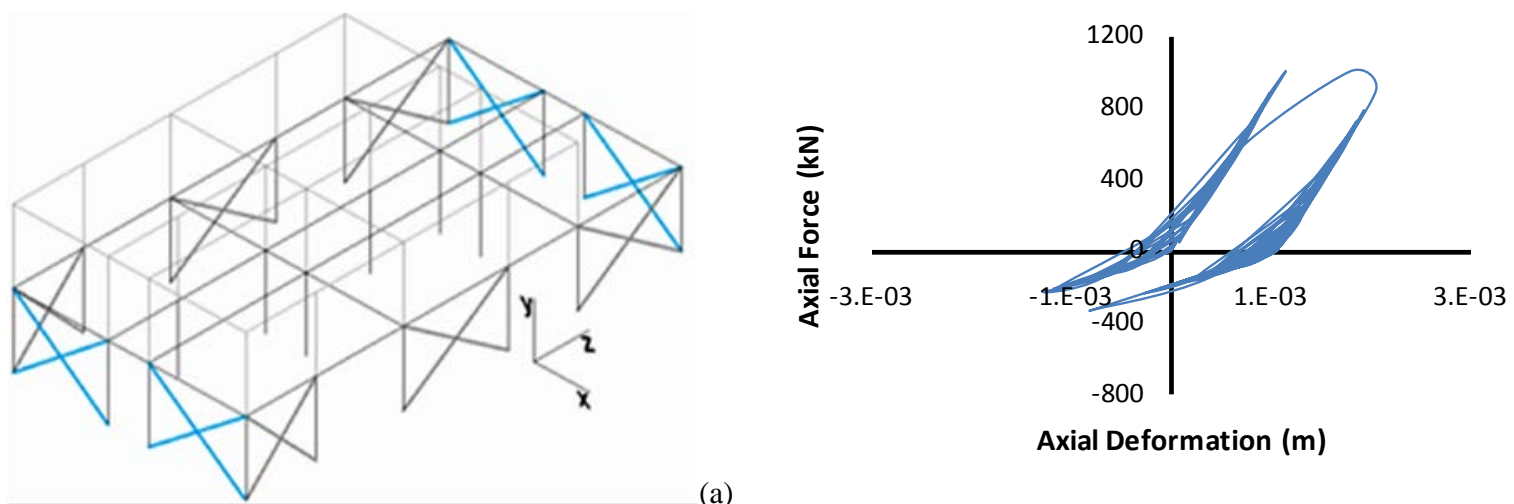

Axial Deformation $(\mathrm{m})$

(b)

Figure 26: (a) Damage Distribution for combination $x+0.3 y$, (b) Hysteresis Diagram of metal brace

Figure 26(a) presents the local nonlinear behavior of the structural members in terms of plastic rotational hinge requirement based on the limit state of the critical sections. For the combination $y+0.3 x$, all the structural members responded elastically. For the combination $\mathrm{x}+0.3 \mathrm{y}$, increased demands are shown only to the metal braces that are situated parallel to the direction of the force. The sections that responded nonlinearly reached the Damage Limitation $(D L)$ limit state. In Figure 26(b) the hysteresis diagram of a metal brace is shown. The damage to the metal braces can be economically repaired.
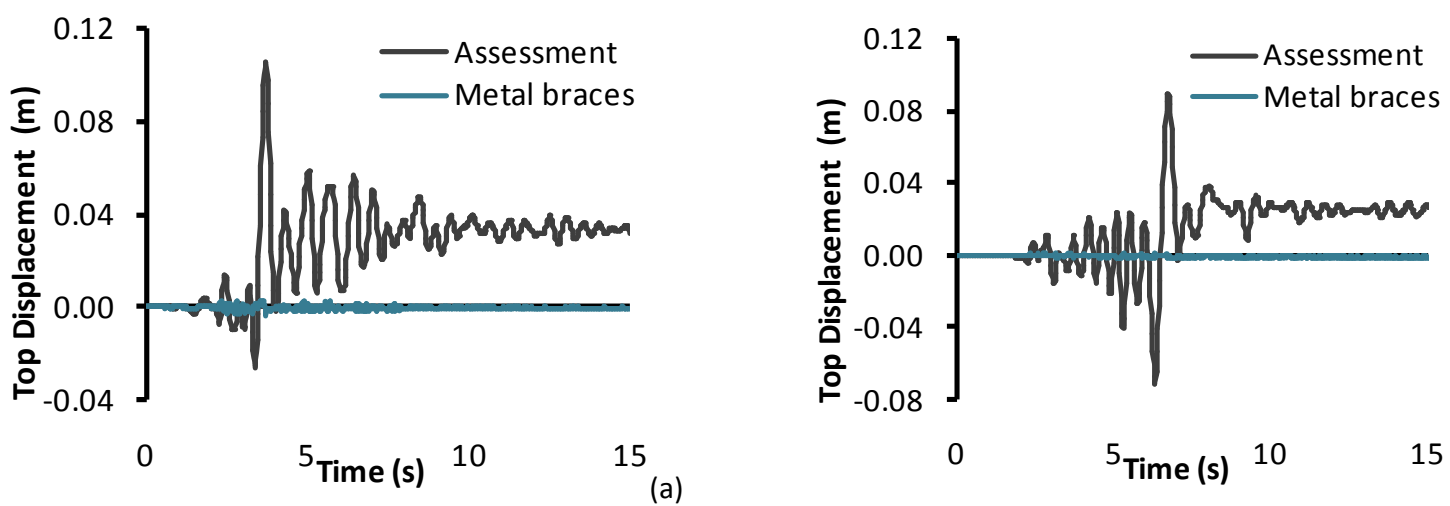

(a)

Figure 27: Top Displacement (a) for combination $x+0.3 y$, (b) for combination $y+0.3 x$ 
In Figure 27 the top displacement of the structure is shown. This diagram represents the behavior of the structure before and after the intervention with metal braces. In the initial stage, the displacements of the top of the building are significantly larger that those after the intervention with the metal braces. In the first case, the maximum top displacement is $0.106 \mathrm{~m}$ while after the intervention the maximum top displacement is $0.0034 \mathrm{~m}$. It is also observed that after the intervention with metal braces, there is no permanent displacement. Before the intervention the permanent displacement of the structure was for both combinations near to $0.03 \mathrm{~m}$.
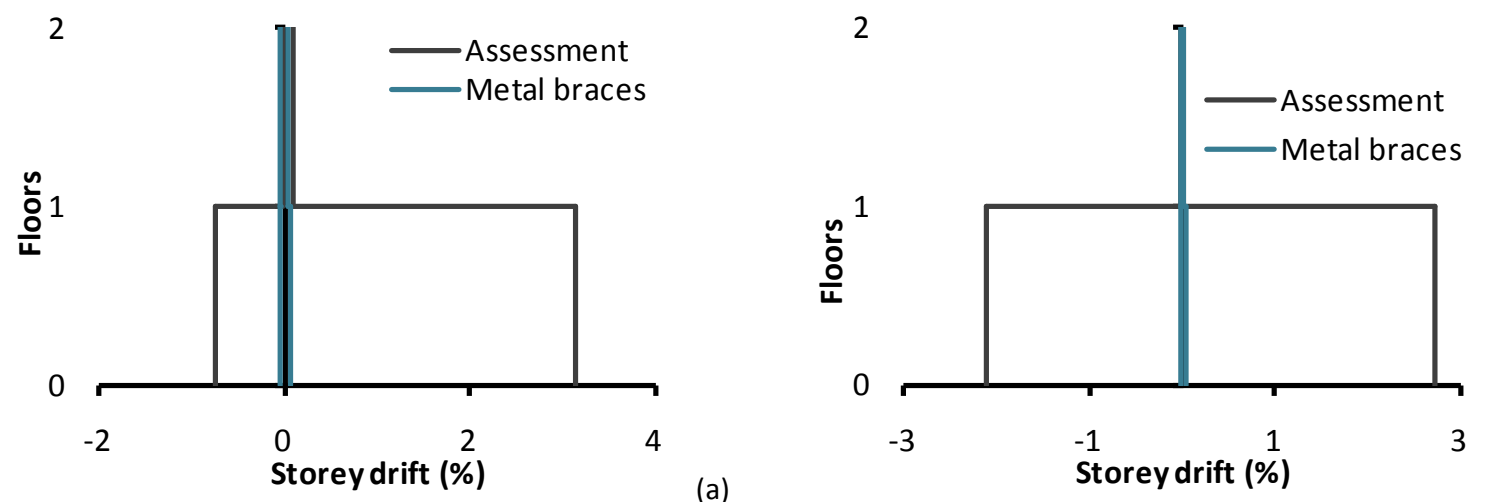

(a)

(b)

Figure 28: Storey Drift Diagram (a) for combination $x+0.3 y$, (b) for combination $y+0.3 x$

In Figure 28, the storey drift for the initial condition and the metal brace intervention is shown. The storey drift is significantly decreased with the use of metal braces. Specifically, for the combination $x+0.3 y$, before the intervention the maximum storey drift is $3.13 \%$ while after the intervention the maximum storey drift is $0.066 \%$. For the combination $y+0.3 x$, before the intervention the maximum storey drift is $2.72 \%$ while after the intervention the maximum storey drift is $0.033 \%$.

In Figure 29, the shear distribution to the floors before and after the intervention is shown. The shear distribution is significantly decreased with the use of metal braces. Specifically, for the combination $\mathrm{x}+0.3 \mathrm{y}$, before the intervention the maximum shear force to the ground floor is near to $2900 \mathrm{kN}$, while after the intervention the maximum shear force to the ground floor is about $320 \mathrm{kN}$. For the combination $\mathrm{y}+0.3 \mathrm{x}$, before the intervention the maximum shear force to the ground floor is about $1900 \mathrm{kN}$, while after the intervention the maximum shear force to the ground floor is about $80 \mathrm{kN}$.
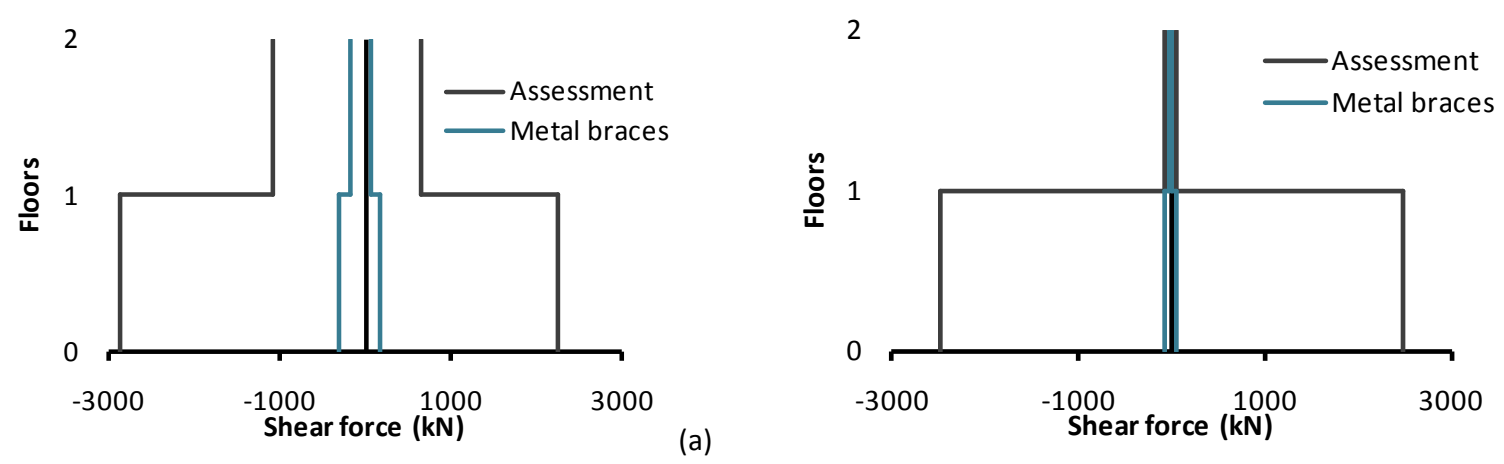

(b)

Figure 29: Shear Distribution per floor (a) for combination $x+0.3 y$, (b) for combination $y+0.3 x$ 


\section{CONCLUSION}

Firstly, the assessment of the building with nonlinear analysis methods took place. As it was expected the building behaved as "pilotis" type. A "soft" floor mechanism was created in the ground floor because of the lack of infill walls there. The columns majority and a great number of beams of the ground floor responded nonlinearly. The structural members of the first floor remained in the elastic range. It was also observed that, at the end of the earthquake, large permanent drifts were present. Finally, the analyses results verified the actual state that was presented by the building after the earthquakes. A "soft" floor mechanism actually occurred, since the columns of the ground floor were heavily damaged and the second floor responded elastically.

Having the assessment procedure carried out, the need for structural intervention has been decided. The first method to be used was the implementation of LRB and FPS isolation systems. As a result, the period of the building was increased and the seismic force demand was reduced. The structural members of the structure and the walls responded linearly. It was observed that the largest side movements were taken over from the bearings, while the rest of the structure moved as a rigid body. The relative displacement between the top and the base of the building decreased about 10 times, while the storey drift of the ground floor decreased 7 times and the shear force of the ground floor 2 times. Moreover, there were no permanent deformations.

The second intervention method to be used was the implementation of metal braces with a SHSH120x120x10 section. As a result, the stiffness and the strength of the building were increased and consequently the period was reduced. The majority of the structural members responded linearly. The majority of the damages concentrated in the metal braces which are considered replaceable. The top displacement of the building was incomparably reduced, while the storey drift of the ground floor was reduced 8 times and the shear force of the ground floor 9 times.

The assessment of the seismic behavior of the building verified the damages that were observed during the field investigation and were expected also according to the scientific knowledge about the "pilotis" type buildings. The intervention to the building was made with two methods which are based in different principles. Both methods were proved to be equally efficient as they were successful in preventing the structural elements from significant yielding and in decreasing the storey drift to a negligible point. Thus, after the interventions the structure is lightly damaged and does not need any repair measures to be taken.

\section{REFERENCES}

[1] M.J. Favvata, M.C. Naoum, C.G Karayannis, Limit States of RC structures with first floor Irregularities. Structural Engineering and Mechanics, 47, 791-818, 2013.

[2] G.E. Thermou, S.A. Elnashai, Seismic retrofit schemes for RC structures and localglobal consequences. Progress in Structural Engineering and Engineering Materials, 8, 1-15, 2006.

[3] R.I. Skinner, W.H. Robinson, G.H. McVerry, An introduction to seismic isolation. John Wiley and Sons, 1993.

[4] F. Naeim, J.M. Kelly, (1999), Design of seismic isolated structures. Wiley, 1999.

[5] T.A. Antonopoulos, S.A. Anagnostopoulos, Seismic evaluation and upgrading of RC buildings with weak open ground stories. Earthquakes and Structures, 3, 611-628, 2012. 
[6] L.Su, G. Ahmadi, J.G. Tadjbakhsh, A comparative study of performances of various base isolation systems, part I: Shear beam structures. Earthquake Engineering and Structural Dynamics, 18, 11-32, 1989.

[7] J.M. Kelly, Earthquake-Resistant Design with Rubber, 2nd Edition. Springer-Verlag, 1997.

[8] M. Constantinou, A. Mokha, and A. Reinhorn, Teflon bearings in base isolation II: Modeling. Journal of Structural Engineering, 116, 455-474, 1990.

[9] Eurocode 8: Design of structures for earthquake resistance, Part 3: assessment and retrofitting of buildings. EN1998-3-2005, European Committee for Standardization (CEN), 2005.

[10] KAN.EPE., Greek Retrofitting Code. Greek Organization for Seismic Planning and Protection (OASP), Greek Ministry for Environmental Planning and Public Works, Athens, 2012.(In Greek)

[11] RD, Earthquake design regulation of building works, Royal Decree (19/26.02.1959), Ministry of Public Works, Greece, 1959. (In Greek)

[12] T. Takeda, M.A. Sozen, N.N Nielson, Reinforced concrete response to simulated earthquakes. Journal of Structural Division ASCE, 96, 2557-2573, 1970.

[13] E. Spacone, F.C. Filippou, F.F. Taucer, Fibre beam-column model for non-linear analysis of RC frames: Part I: Formulation. Earthquake Engineering and Structural Dynamics, 25, 711-725, 1996.

[14] E. Spacone, and F.C. Filippou, F.F. Taucer, Fibre beam-column model for non-linear analysis of RC frames: Part II: Applications. Earthquake Engineering and Structural Dynamics, 25,727-742, 1996.

[15] C. Karayannis, M. Favvata, Application of ATC40 and FEMA nonlinear static analysis procedures for the evaluation of RC frame structures. Scientific Review KTIRIO, A-B, 95-104, 2003.(In Greek)

[16] Eurocode 8: Design of structures for earthquake resistance, Part 1: General rules, seismic actions and rules for buildings. EN 1998-1:2004, European Committee for Standardization (CEN), 2004.

[17] Y.K. Wen, Method for random vibration of hysteretic systems. Journal of the Engineering Mechanics Division, 102, 249-263, 1976.

[18] Y.J Park, Y.K Wen, A.H.S Ang, Random vibration of hysteretic systems under bidirectional ground motions. Earthquake Engineering and Structural Dynamics, 14, 543-557, 1986.

[19] S. Nagarajaiah, A.M Reinhorn, M.C. Constantinou, 3D-Basis: Non-Linear Dynamic Analysis of Three-Dimensional Base Isolated Structures: Part II, Technical Report NCEER-91-0005, National Center for Earthquake Engineering Research, State University of New York at Buffalo, Buffalo, USA, 1991.

[20] V.A. Zayas, S.S. Low, S.A. Mahin, A simple pendulum technique for achieving seismic isolation. Earthquake Spectra, 6, 317-334, 1990. 